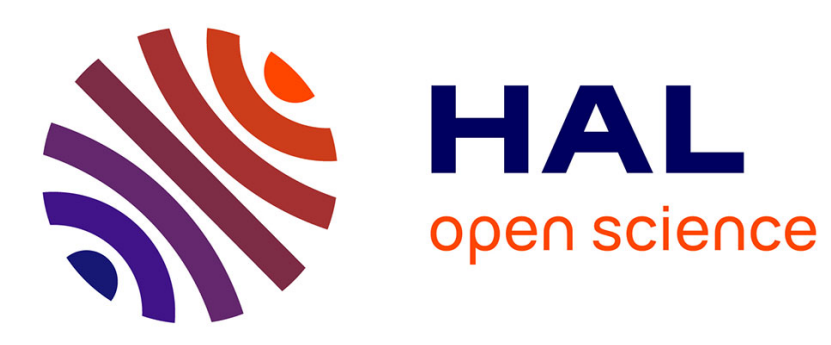

\title{
Merger Guidelines for Bidding Markets
}

Philippe Gagnepain, David Martimort

\section{To cite this version:}

Philippe Gagnepain, David Martimort. Merger Guidelines for Bidding Markets. Revue Economique, 2016, Nouveaux regards en économie et politique de la concurrence, 67 (Hors-série), pp.69-78. 10.3917/reco.hs01.0069 . hal-01314036

\section{HAL Id: hal-01314036 https://hal.science/hal-01314036}

Submitted on 12 May 2016

HAL is a multi-disciplinary open access archive for the deposit and dissemination of scientific research documents, whether they are published or not. The documents may come from teaching and research institutions in France or abroad, or from public or private research centers.
L'archive ouverte pluridisciplinaire HAL, est destinée au dépôt et à la diffusion de documents scientifiques de niveau recherche, publiés ou non, émanant des établissements d'enseignement et de recherche français ou étrangers, des laboratoires publics ou privés. 


\title{
Merger Guidelines for Bidding Markets ${ }^{1}$
}

\author{
Philippe Gagnepain ${ }^{2}$ and David Martimort ${ }^{3}$
}

October 9, 2015

\begin{abstract}
We propose merger guidelines for bidding markets through the construction of a simple test. It is applied in the particular context of the French urban transport industry. It designs the optimal auction and captures two opposite forces at stake: On the one hand, the optimal auction is biased against a merger due to a loss of competition; on the other hand, potential efficiency gains bias the optimal allocation towards the merger firm. The two effects can be nested in a single equation condition which determines whether the merger improves the consumer net surplus. We suggest that the merger between Transdev and Veolia is consumer surplus improving if the efficiency gains from the merger allow both firms to decrease their initial costs inability by at least 17.9 and 17.8 percent respectively.
\end{abstract}

\section{Résumé}

Nous proposons un test simple qui détermine si une fusion entre entreprises devrait ou non être autorisée dans une industrie qui sélectionne les candidats à l'exploitation par des d'appels d'offre. Ce test est appliqué dans le cas particulier de l'industrie du transport urbain en France. Il élabore l'enchère optimale et tient compte de deux effets antagonistes : d'une part, la fusion est préjudiciable car elle entraine une perte de concurrence ; d'autre part, les gains d'efficacité potentiels jouent en faveur des entreprises qui fusionnent. Les deux effets peuvent être incorporés dans une unique condition qui détermine si la fusion permet d'améliorer le surplus net du consommateur. Nos résultats suggèrent que la fusion entre Transdev and Veolia améliore le surplus net du consommateur si les gains d'efficacités issus de la fusion permettent aux deux entreprises de diminuer leur inefficacité en termes de coûts d'au moins 17.9 et 17.8 pour cent respectivement.

Codes JEL : L51, C51, and L92.

\footnotetext{
${ }^{1}$ We thank two referees for very helpful comments, and Joanna Piechucka for superb research assistance. The authors received financial support from the Agence Nationale pour la Recherche (ANR).

${ }^{2}$ Paris School of Economics-Université Paris 1, 106-112 Boulevard de l'Hôpital, 75647 Paris Cedex 13, France (e-mail: philippe.gagnepain@univ-paris1.fr).

${ }^{3}$ Paris School of Economics-EHESS, 48 boulevard Jourdan, 75014 Paris, France (e-mail: david.martimort@parisschoolofeconomics.eu).
} 


\section{INTRODUCTION}

The evaluation of the welfare effects of a merger between two companies in public procurement is a crucial issue. In the French urban transport industry, firms are granted the right to operate a network after they have participated in a competitive tender. Thus, operators compete for the market and the winner is the one who announces the lowest service cost. Economic theory suggests that the participation of a larger number of entities in a tender increases the intensity of the ex ante competition and is thus beneficial to society. Hence, a merger is potentially harmful to competition, since it reduces the amount of ex ante competitors, and it should be accepted by the competition authority only if it guarantees sufficient efficiency gains to the firms that join their productive forces.

In this context, the recent merger in March 2011 of two of the biggest urban transport operators, Veolia Transport and Transdev, is of particular importance, given that, before the merger, about eighty percent of local transport service operators were owned by Veolia Transport, Transdev, and a third operator, Keolis. Whether this recent decision has allowed an improvement of the consumer surplus is a key issue that needs to be addressed empirically.

In this article, we propose merger guidelines for bidding markets through the construction of a simple test which can be easily implemented by a regulator or a competition authority. We apply our test in the particular context of the French urban transport industry, using data on transport operators from 1995 to 2010, i.e., before the merger has been implemented. Our test is based on a structural model of competitive bidding. It designs the optimal auction and captures two opposite forces at stake: On the one hand, the optimal auction is biased against a merger due to a loss of competition. On the other hand, potential efficiency gains bias the optimal allocation towards the merger firm. The two effects can be nested in a single equation condition which determines whether the merger is consumer surplus improving. Our test requires the practitioner to have a good understanding of the cost structure of the industry. In particular, it is necessary to recover information on the unobserved cost ability of the transport operators. We propose here to estimate a cost function to evaluate more precisely the technology of the industry. The cost structure includes a deterministic component which entails the usual cost ingredients which are common knowledge to all firms in the industry, and an unobserved cost ability variable, which is firm specific. Our tests evaluate the minimum level of efficiency gains obtained from the merger which guarantee an improvement of the consumer surplus.

The next section presents the model of competitive bidding from which a consumer surplus improving condition is derived. Section 3 describes the French urban transport 
industry. Section 4 proposes an overview of our dataset. Section 5 is dedicated to our empirical test. Section 6 concludes.

\section{THE MODEL}

We consider a bidding market for a unitary service with $n$ firms indexed by $i=$ $1, \ldots, n$ whose costs are independently distributed and drawn from the common knowledge distributions $F_{i}(\cdot)$, with atomless and positive density $f_{i}(\cdot)$. We impose the regularity condition of Monotonicity of the hazard rate:

$$
\frac{d}{d \theta}\left(\frac{F(\theta)}{f(\theta)}\right)>0 .
$$

Consumers enjoy a surplus $S$ if the unit service is produced. Suppose first that firms adopt a Bayesian-Nash behavior. From Myerson [1981], the optimal auction that maximizes the consumer net surplus selects firm $i$ whose virtual cost is the lowest provided the net surplus is positive. The condition is to select $i_{0}$ such that

$$
i_{0}=\arg \min _{i} \theta_{i}+\frac{F\left(\theta_{i}\right)}{f\left(\theta_{i}\right)}
$$

provided that

$$
S>\theta_{i_{0}}+\frac{F\left(\theta_{i_{0}}\right)}{f\left(\theta_{i_{0}}\right)} .
$$

In case of a tie (probability zero), we just choose the service provider with equal probability among those having the lowest virtual costs. From now on, we shall assume that all distributions are alike, i.e., $F_{i}=F$ for all $i$. We now consider a merger between two firms, say 1 and 2 . Their common cost after the merger is

$$
\theta_{M}=\min \left(\theta_{1}, \theta_{2}\right)-\eta
$$

The parameter $\eta$ represents the efficiency gains from the merger. We assume for simplicity that this parameter is common knowledge. The post-merger cost $z=\min \left(\theta_{1}, \theta_{2}\right)$ net of efficiency gains is drawn from a distribution $F^{2}(z)$ whose density is $2 f(z) F(z)$ and whose hazard rate is thus $2 \frac{F(z)}{f(z)}$. The merged firm is optimally chosen as the auction winner when:

$$
z-\eta+2 \frac{F(z)}{f(z)} \leq \min _{i \geq 3} \theta_{i}+\frac{F\left(\theta_{i}\right)}{f\left(\theta_{i}\right)}
$$


Let us compare with the pre-merger case condition (1) when either firm 1 or 2 is optimally selected. This latter condition can be rewritten as

$$
z+\frac{F(z)}{f(z)} \leq \min _{i \geq 3} \theta_{i}+\frac{F\left(\theta_{i}\right)}{f\left(\theta_{i}\right)}
$$

Two effects are at play. On the one hand, there is less competition following the merger. The virtual cost of the merger is always greater than the minimal virtual cost of the separate units; an extra term $\frac{F(z)}{f(z)}$ is at play on the left-hand side of (3). The optimal auction would thus be biased against that merger if there was no efficiency gains. On the other hand, the merger brings efficiency gains. Those efficiency gains reduce the perceived virtual cost of that merger and now bias the optimal allocation towards the merger firm. The merger is consumer surplus improving when (3) is obtained. That condition provides our merger guidelines for bidding markets.

\section{DESCRIPTION OF THE INDUSTRY}

Our empirical application focuses on the French urban transportation industry. As in most countries around the world, urban transportation in France is a regulated activity. Local transportation networks cover each urban area of significant size, and for each network, a local authority (a municipality, a group of municipalities or a district) is in charge to regulate an operator which has been selected to provide the transportation service. Regulatory rules prevent the presence of several suppliers of transportation services on the same urban network, and each network is therefore operated by a single operator.

The 1982 Transportation Law was enacted to facilitate decentralized decision-making on urban transportation and to provide guidelines for regulation. As a result, each local authority now organizes its own transportation system by setting route and fare structures, capacity, quality of service, conditions for subsidizing the service, levels of investment and ownership nature. The local authority may decide to operate the network directly or to require the services of a transport service provider. In the latter case, a formal contract defines the regulatory rules that the operator must follow as well as the payment and/or cost-reimbursement scheme between the authority (the principal) and the operator (the agent). In most urban areas, operating costs are on average twice as high as commercial revenues. Budgets are therefore rarely balanced without subsidies. One reason is that operators face universal service obligations and must operate in low demand areas. Low prices are maintained to ensure affordable access to all consumers of public transportation. Moreover, special fares are given to targeted groups like seniors and students. Subsidies come from the State's budget, the 
local authority's budget, and a special tax paid by local firms (employing more than nine full-time workers). They are not necessarily paid directly to the operator. In addition to the price distortions causing deficits, informational asymmetries that affect the cost side and lead to inefficiencies make it more difficult to resume these deficits.

A distinguishing feature of France compared to most other OECD countries is that about eighty percent of local operators are private and are owned by three large companies, two of them being private while the third one is semi-public. In 2002, these companies, with their respective ownership structures and market shares (in terms of number of networks operated) were Keolis (private, 30\%), Transdev (semi-public, $19 \%$ ), Connex (private, $25 \%$ ). In addition there are a small private group, Agir, and a few public firms controlled by local governments.

Industrial groups of urban transport have a long history of mergers in France. Keolis was born out of the merger of several companies created in the beginning of the 20th century. The Société des transports automobiles, created in 1908, its subsidiary (the Société générale des transports départementaux) and the company Lesexel, founded in 1911 to help on the development of tramways, merged to form the VIA-GTI company, mainly focused on urban transport. In the meantime, another company, Cariane, was specialized in the French interurban transport. Ultimately, VIA-GTI and Cariane merged in 2001 to give birth to Keolis. The industrial group Connex was born out of the merger of the Compagnie Générale Française des Transports et Entreprises (CGFTE) and the Compagnie Générale d'Entreprises Automobiles (CGEA) in the late 1980's. The company was ultimately renamed Veolia Transport in 2005. Finally, the Transdev group was created in 1955. On March 3rd 2011, it merged with Veolia Transport to give birth to Veolia Transdev. The French Competition Authority cleared the merger but required both parties to finance the creation of a competition stimulation fund (Décision 10-DCC-198, December 30th, 2010). ${ }^{4}$ This fund would, in particular, allow regulators to compensate all or part of the expenses for candidates not selected during the calls for tenders, in order to encourage more competitors to take part in them. By stimulating the number of submitted tenders, these measures are intended to intensify competition during calls for tenders.

For each urban transport network, the automatic renewal of the contract between the local authority and the operator in place was effectively ended, by law, in 1993. Since then, local authorities are required to use tenders to allocate the construction and management of infrastructures of urban transportation. The public notice of call for applications states the qualifications and skills required of candidates, and lists the set

\footnotetext{
${ }^{4}$ The full text of the decision is available at http:/ / www.autoritedelaconcurrence.fr/pdf/ avis/10DCC198decisionoccultee.pdf
} 
of objectives to be fulfilled, including the quality of the service which entails various dimensions such as the size of the network, the number and size of lines, the number of stops, the frequency of the service, and the age of the rolling stock. The winning bidder is the firm which proposes to operate the service at the lowest cost. ${ }^{5}$

Note that our aim in this article is to propose general merger guidelines which can be applied in an industry where ex ante competition is assumed to work reasonably well. ${ }^{6}$ If this not the case, further research is needed in order to determine how the two main effects of a merger (reduced competition and efficiency gains) are affected. We leave this discussion for future research.

\section{THE DATA}

We exploit a database that was created in the early 1980s from an annual survey conducted by the Centre d'Etude et de Recherche du Transport Urbain (CERTU, Lyon) with the support of the Groupement des Autorités Responsables du Transport (GART, Paris), a nationwide trade organization that gathers most of the local authorities in charge of a urban transport network. In France, this rich source is a unique tool for comparing observed regulatory schemes both across year and over time. The sample does not include the largest networks of France, i.e., Paris, Lyon and Marseille, as they are not covered by the survey. Overall, the panel data set covers 158 different urban transport networks over the period 1995-2010.

To estimate a cost function, we recover information on the level of operating costs, the quantity of output, and the input prices. Total costs $C$ are defined as the sum of labor and material costs. Output $Q$ is measured by the number of seat-kilometers. The Infrastructure $I$, which also plays the role of a fixed input, is measured by the total length of the transport network in kilometers. Since the authority owns the capital, the operators do not incur capital costs. The average wage rate $w_{L}$ is obtained by dividing total labor costs by the annual number of employees. The price of materials $w_{M}$ is constructed by dividing the total fuel expenditures by the quantity of fuel consumed.

\footnotetext{
${ }^{5}$ Examples of calls for tenders in the French public transit industry can be found at http:/ / www.villerail-transports.com/appels-d-offres.

${ }^{6}$ The three main operators have been condemned in 2005 by the French Competition Authority (decision 05-D-38) for collusive agreements during the period 1996- 1998, which obviously casts doubts on the effectiveness of ex ante competition over this period.
} 


\section{EMPIRICAL ANALYSIS}

The operating costs $C_{i t}$ of the firms are the main ingredient of our analysis on bidding markets. We distinguish the deterministic part of the cost expression $\bar{C}_{i t}$, which is common to all firms in the industry, from the individual cost ability parameter $\theta_{i}$, which is specific to firm $i$ only, and is unknown to the regulator. Thus,

$$
C_{i t}=\bar{C}_{t i}\left(w_{L_{i t}}, w_{M_{i t}}, Q_{i t}, I_{i t}\right) \exp \left(\theta_{i}\right),
$$

where $\bar{C}_{i t}$ depends on the total quantity produced $Q_{i t}$, the network size $I_{i t}$, the price of labor $w_{L_{i t}}$, and the price of material $w_{M_{i t}}$. Adding an error term $\epsilon_{i t}$ to the right hand side of (8), we obtain the cost function to be estimated:

$$
\begin{aligned}
\ln C_{i t}^{*}= & \beta_{L} \ln w_{L_{i t}}^{*}+\beta_{Q} \ln Q_{i t}+\beta_{I} \ln I_{i t}+\beta_{L L}\left(\ln w_{L_{i t}}^{*}\right)^{2}+\beta_{Q Q}\left(\ln Q_{i t}\right)^{2} \\
& +\left(\beta_{I I} \ln I_{i t}\right)^{2}+\beta_{L Q} \ln w_{L_{i t}}^{*} \ln Q_{i t}+\beta_{L I} \ln w_{L_{i t}}^{*} \ln I_{i t}+\beta_{Q I} \ln Q_{i t} \ln I_{i t} \\
& +\theta_{i}+\epsilon_{i t},
\end{aligned}
$$

where, from the condition of homogeneity of degree one in input prices,

$$
\begin{aligned}
\ln C_{i t}^{*} & =\ln C_{i t}-\ln w_{M_{i t}}, \\
\ln w_{L_{i t}}^{*} & =\ln w_{L_{i t}}-\ln w_{M_{i t}} .
\end{aligned}
$$

The main parameter of interest in the cost expression is the unobserved cost ability parameter $\theta_{i}$. To test the consumer surplus improving condition in (3), we need to recover an individual evaluation $\hat{\theta}_{i}$. To do so, $\theta_{i}$ is considered as a fixed effect in the course of the estimation of (6), and is therefore decomposed as $\theta_{i}=\theta_{0}+\theta_{0 i}$, where $\theta_{0}$ is a constant, and $\theta_{0 i}$ is specific to the $158-1$ firms of our sample.

We consider here an oversimplified cost estimation model, which may not be the best choice for achieving a good approximation of the true cost function, but allows us to facilitate the interpretability and tractability of our merger guidelines. The fit of our cost structure could be improved in several ways. First, following Gagnepain and Ivaldi [2002], costs should depend on the type of regulatory contract (cost-plus or fixed-price) faced by the transport operator, as the former strongly influences the cost reducing activity of the latter. Second, the efficiency parameter is independent of time, which is debatable. This implies that contracts are renewed independently of the past state of nature. In a dynamic setting, the cost ability parameter $\theta_{i}$ could evolve, and its evolution could be approximated by a trend. (See Cornwell, Schmidt, and Sickles, 1990, for such a model.) Third, the distribution of $\theta_{i}$ could as well be dictated by the 
political history of the network and the political agenda of the local authorities, see Gagnepain and Ivaldi, [2015]. Fourth, the $\theta_{i}$ s differ across networks and are independent, although most operators belong to three industrial groups, Transdev, Veolia, and Keolis. We believe that the characteristics of each network differ from one city to the next. The managers' ability to use efficient amounts of labor, material, and even fuel may differ from one network to another, even if the workers have similar skills ex ante. In addition, conflicts with worker unions, social and security problems, or externalities like traffic congestion are clearly idiosyncratic phenomena. Hence the ability level $\theta_{i}$ pertains to the network itself. Future research could relax this assumption and account for the effect of the manager's "culture" which is specific to the identity of the industrial groups that own the observed network. Finally, these industrial groups may also operate other municipal services such as water distribution or garbage collection, which may impact the operating costs of their transportation activity, see Desrieux et al. [2013]. At this stage, we do not have any data on these other services.

The results of the estimation of the cost expression (6), using a simple fixed effect procedure, are presented in Table 1 . Most of the parameters are significant at the 5 percent level. The goodness of fit of our function is satisfactory as suggested by the $R$ squared. An individual evaluation $\hat{\theta}_{i}$ is obtained from the estimated $\widehat{\beta}$. Figure 1 provides a non-parametric representation of the density $f\left(\theta_{0 i}\right)$. Individual values $F\left(\theta_{0 i}\right)$ can be obtained as well for each $\theta_{0 i}$.

We are now ready to illustrate our methodology using data on Transdev and Veolia, two of the largest urban transport operators in France, which merged in 2011. We have suggested that the merger is consumer welfare improving if

$$
z+2 \frac{F(z)}{f(z)}-\eta \leq \min \theta_{i}+\frac{F\left(\theta_{i}\right)}{f\left(\theta_{i}\right)}, i \in\{\text { Transdev, Veolia, Keolis }\}
$$

On the left-hand side of this expression, $z=\min \left(\theta_{\text {Transdev }}, \theta_{\text {Veolia }}\right)$ is the cost ability parameter of the merged entity, which is equivalent to the lowest cost ability parameter among those of Transdev and Veolia. Moreover, $\eta$ represents the efficiency gains from the merger, which are unknown to us. On the right-hand side, $\theta_{i}$ is the cost ability parameter of each firm, namely Transdev, Veolia, and Keolis, before the merger takes place.

Since the dataset covers the period 1995-2010, we have no information about firms' costs after the merger is effective (in 2011). We are however able to compute from Equation (7) the minimum efficiency gains $\eta$ required to guarantee that the merger is consumer welfare improving. Since each firm is present in several networks simultaneously, we compute the average $\theta_{\text {Transdev }}, \theta_{\text {Veolia }}$, and $\theta_{\text {Keolis }}$ from the individual fixed 
effects estimated previously. They are equal to $4.98,4.99$, and 4.86 respectively, which suggests that the two merging firms are characterized by a similar cost ability parameter, while Keolis is the most efficient operator (the one with the lowest cost ability parameter).

Table 2 lists the different ingredients, $\theta_{i}, f\left(\theta_{i}\right)$, and $F\left(\theta_{i}\right)$ for each operator. From (10), the merger is consumer surplus improving if $4.98+2 \frac{F(4.98)}{f(4.98)}-\eta \leq 4.86+\frac{F(4.86)}{f(4.86)}$, i.e., if $\eta \geqslant 0.891$. Hence, the efficiency gains from the merger must allow Transdev and Veolia to decrease their initial costs ability parameter by at least 17.9 and 17.8 percent respectively. Whether this merger has allowed to improve consumer surplus could be tested by comparing these estimated values to the real efficiency gains obtained after the merger started working in 2011. To do so, we need to collect additional data from 2011.

\section{CONCLUSION}

To evaluate the future impact of a merger on consumers' surplus is an important task for the regulator. In this paper, we propose a simple test which consists in identifying the minimal level of efficiency gains from the merger which allows the later to improve consumers' surplus. The test requires a good understanding of the cost structure of the industry under scrutiny, and in particular, to be able to recover individual measures of the cost ability parameters for each firm of the industry.

Our analysis calls for a main alley for further investigation: Being able to evaluate the actual efficiency gains of the merger remains an open question which is not addressed here. The economic literature interested in merger simulation usually focuses on the demand side of the analysis and assumes different ad hoc scenarios of cost reduction after the merger, see Davis and Garcés [2009] for instance. There is therefore a need for analytical tools that would help describe the cost side of the analysis. The evaluation of the efficiency gains after the merger through the estimation of a cost function, like the one presented in this paper, is a particularly promising candidate. If valid information on the efficiency gains is available, the practitioner should simply clear a merger if the minimal level of efficiency gains computed in this paper is at least equal to the actual efficiency gains. 
[1] CORNWELL, C., SCHMIDT, P., AND SICKLES, R.C. [1990], "Production Frontiers with Cross-sectional and Time-Series Variation in Efficiency Levels", Journal of Econometrics, 46, p. 185-200.

[2] DAVIS, P., \& GARCÉS, E. [2009], Quantitative techniques for competition and antitrust analysis. Princeton University Press.

[3] DESRIEUX, C., CHONG, E., \& SAUSSIER, S. [2013], Putting all one's eggs in one basket: Relational contracts and the management of local public services, Journal of Economic Behavior \& Organization, 89, p. 167-186.

[4] GAGNEPAIN, P., AND M. IVALDI. [2002], "Incentive regulatory policies: the case of public transit systems in France", RAND Journal of Economics, p. 605-629.

[5] GAGNEPAIN, P., AND M. IVALDI. [2015], “Contract choice, incentives, and political capture in public transit". mimeo.

[6] MYERSON, R. B. [1981], “Optimal auction design”, Mathematics of operations research, 6(1), 58-73. 
Table 1: Estimation results

Parameter Estimate

$\theta_{0} \quad 4.936$

(1.654)

$\beta_{L} \quad 2.772$

$(0.259)$

$\beta_{Q} \quad-0.063$

(0.268)

$\beta_{I} \quad-1.336$

$(0.207)$

$\beta_{L L} \quad 0.020$

(0.008)

$\beta_{L Q} \quad-0.215$

(0.031)

0.111

(0.040)

$-0.007$

(0.011)

0.182

(0.024)

0.182

(0.024)

Firms FE Yes

Years FE Yes

$R^{2} \quad 0.82$

\# Obser. $\quad 1781$

\# Firms

158

Table 2: Merger Simulation

\begin{tabular}{lrrrrr}
\hline Operator & $\theta_{0 i}$ & $\theta_{i}=\theta_{0}+\theta_{0 i}$ & $f\left(\theta_{i}\right)$ & $F\left(\theta_{i}\right)$ & $\theta_{i}+\frac{F\left(\theta_{i}\right)}{f\left(\theta_{i}\right)}$ \\
\hline Transvev & 0.05 & 4.98 & 0.76 & 0.54 & 5.69 \\
Veolia & 0.06 & 4.99 & 0.76 & 0.54 & 5.70 \\
Keolis & -0.07 & 4.86 & 0.70 & 0.46 & 5.51 \\
\hline
\end{tabular}


Figure 1: Distribution $\theta_{0 i}$

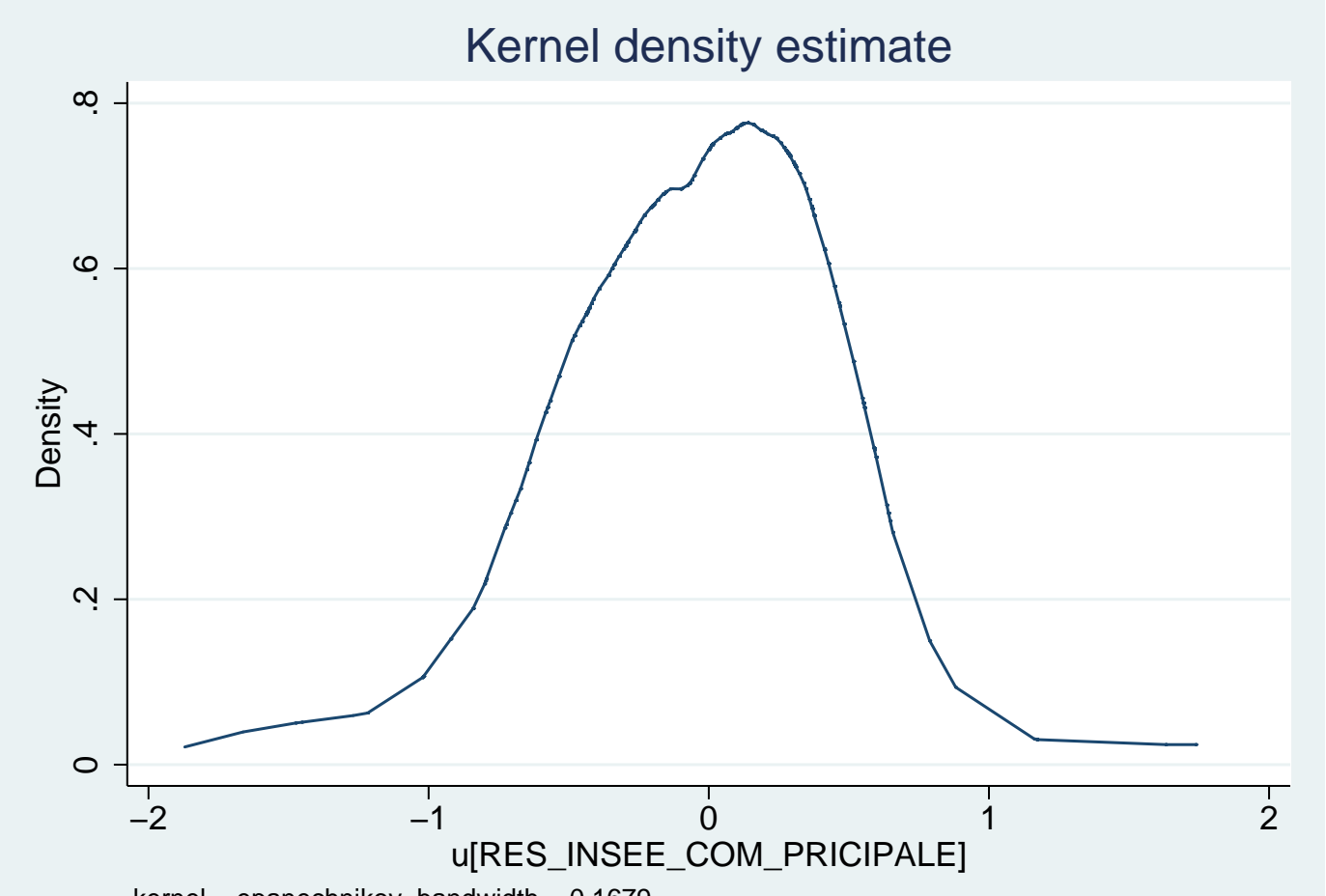

kernel $=$ epanechnikov, bandwidth $=0.1679$ 